\title{
Investigation on potential malaria vectors (Anopheles spp.) in the Province of Trento, Italy
}

\author{
Valentina Tagliapietra ${ }^{1 *}$, Daniele Arnoldi ${ }^{1}$, Marco Di Luca² ${ }^{2}$ Luciano Toma ${ }^{2}$ and Annapaola Rizzoli ${ }^{1}$
}

\begin{abstract}
Background: Europe and Italy were declared malaria free since the 1970s although the presence of competent vectors and the high number of yearly imported malaria cases make this disease a potential rising health issue. In September 2017, a cryptic fatal case of Plasmodium falciparum malaria in the Province of Trento, Italy, raised the concern of health authorities on the possible resurgence of this disease in the Mediterranean Basin.

Methods: An entomological surveillance by means of BG traps, CDC light traps and larval search was performed. Sites were chosen among urban and suburban environments (e.g. private houses, public parks, schools, cemeteries, ecotone urban/forest, farms), ranging from an altitude of 91 to $1332 \mathrm{~m}$ above sea level. All the mosquitoes collected were morphologically identified and about half of them $(103 ; 49 \%)$ were confirmed with the sequencing analysis of the rRNA internal transcribed spacer 2 (ITS-2).

Results: In the present study 287 sites were screened for the presence of Anopheles spp. and 211 specimens were collected and identified. Hundred-eighteen individuals (56\%) belonged to Anopheles plumbeus, 56 (26.5\%) to Anopheles maculipennis complex, 10 (4.7\%) to Anopheles claviger and 27 were identified only at genus level. This is the first record for the presence of An. plumbeus in the study area.

Conclusions: The presence of Anopheles spp. mosquitoes in the Province of Trento, Italy, has been updated with the occurrence of An. plumbeus. The risk of malaria endemicity in the area is to be considered very low, but urban and peri-urban habitat may act as potential breeding sites for the presence of mosquito vectors and should be constantly monitored.
\end{abstract}

Keywords: Malaria vectors, Anopheles spp., Province of Trento, Italy

\section{Background}

Europe and Italy were declared malaria free since the $70 \mathrm{~s}$ although the presence of competent vectors, mainly belonging to the Anopheles maculipennis complex, and the high number of yearly imported malaria cases make this disease a potential rising health issue [1]. In September 2017, an autochthonous fatal case of Plasmodium falciparum malaria in the Province of Trento, Italy-later confirmed as due to hospital-acquired infection [2]attracted the attention of the media, health authorities and scientific community about the potential occurrence

\footnotetext{
*Correspondence: valentina.tagliapietra@fmach.it

${ }^{1}$ Fondazione Edmund Mach, Research and Innovation Centre,

Via E. Mach 1, San Michele all'Adige, Trento, Italy

Full list of author information is available at the end of the article
}

of malaria vectors in this area and in the whole Mediterranean Basin.

Several Anopheles species (Diptera, Culicidae) with variable susceptibility and capability to transmit the infection by Plasmodium spp. occur widely all over Europe, even if their exact distribution is still poorly known. The most important belong to the An. maculipennis complex (An. maculipennis sensu lato), while others (Anopheles algeriensis, Anopheles claviger, Anopheles hyrcanus, Anopheles plumbeus, Anopheles superpictus) have historically played a minor role as secondary vectors, although their vectorial competence is being reevaluated [1]. In particular, An. plumbeus proved to have some receptivity towards $P$. falciparum and, therefore, it was suspected to be involved in cryptic malaria transmission in CentralWestern Europe [3]. 
In Italy, the presence of different Anopheles species is well-known only in very limited areas [4]. Conversely, in many regions the distribution of such species is completely unknown or should be updated, as targeted entomological surveys have been conducted only in the past [5]. In the present study, the results of a 10-year monitoring on the occurrence and distribution of Anopheles spp. mosquitoes in the Province of Trento, Italy are presented.

\section{Methods}

An entomological surveillance on endemic and alien species of mosquitoes has been carried out from 2008 to 2018 in the Province of Trento, Italy, by means of BG traps (Biogents AG, Germany), CDC light traps (http:// www.pepinfest.com) and larval search. The study area has an extension of $6212 \mathrm{~km}^{2}$, is mountainous, with more than $70 \%$ of the territory over $1000 \mathrm{~m}$ above sea level (a.s.l.), is forested, with $55 \%$ of the surface covered by coniferous and deciduous woods, and has a temperateoceanic climate with four main areas: sub-Mediterranean (close to Lake Garda with mild winters), subcontinental (the main valleys with more severe winters), continental (the alpine valleys) and alpine (the areas above the tree line) [6]. A total of 287 sites were screened for the presence of immature or adult stages of Anopheles spp. (see Fig. 1). Trapping period started from the end of April to the beginning of November. BG and CDC light traps were always provided with lure (BG-Lure, Biogents AG, Germany), while $\mathrm{CO}_{2}$ (dry ice) was not regularly added to $\mathrm{BG}$ traps, according to the different projects running. Traps were activated during no windy or rainy days, and operated for $24 \mathrm{~h}$ with some exceptions (during years 2008 and 2009 in Arco and Riva del Garda traps were active 24/7 the whole season). In some sites (see Table 1), traps were run every other week for the whole trapping season, as part of a regular entomological surveillance, while in others they operated only once in the season (see Table 1). Larval search was performed in the period June-August. Sites were chosen among urban and suburban environments (e.g. private houses, public parks, schools, cemeteries, ecotone urban/forest, farms), ranging from an altitude of 91 to $1332 \mathrm{~m}$ a.s.l. All the individuals collected were morphologically identified $[7,8]$. To confirm the reliability of species identification and assess

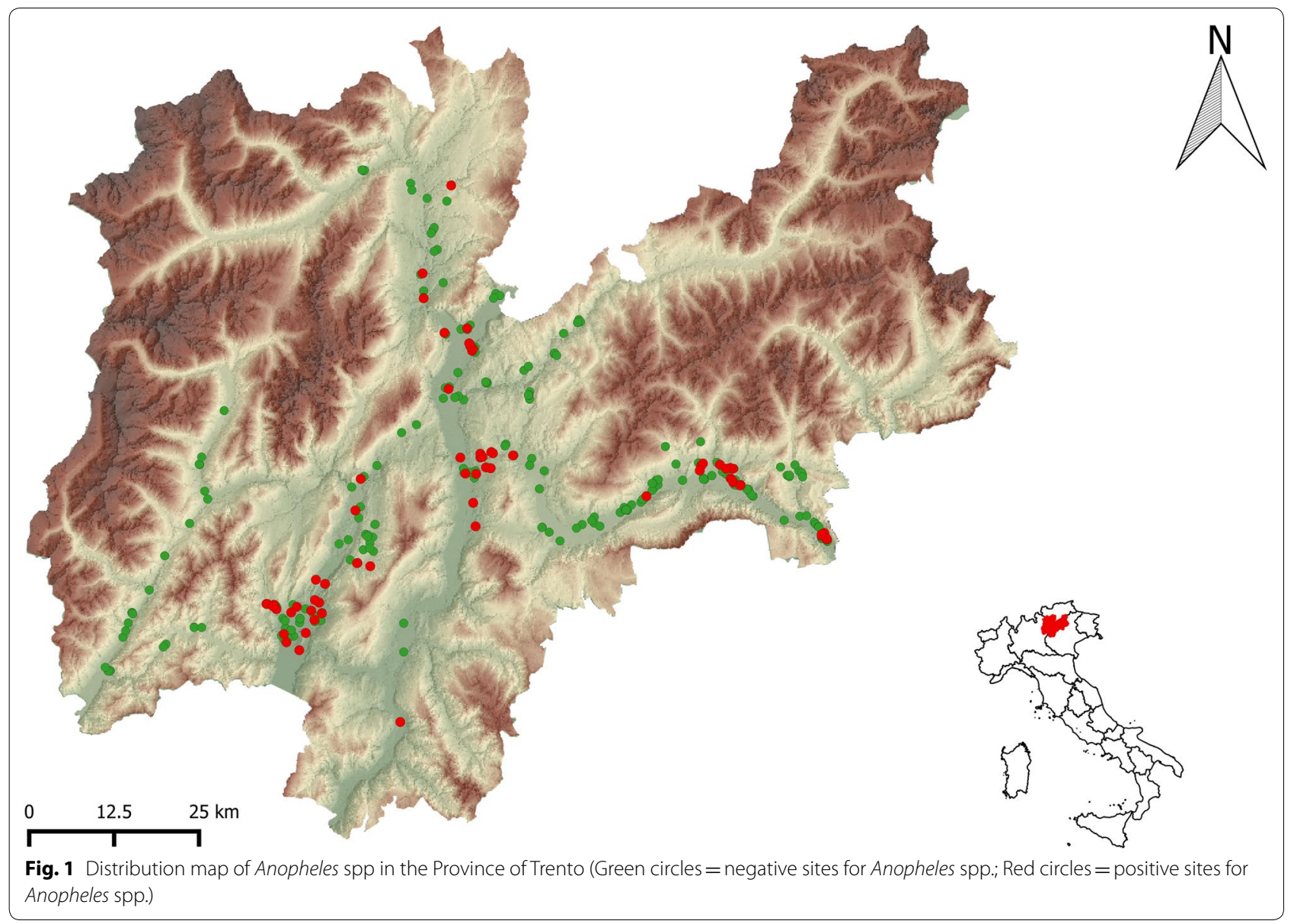


Table 1 Anopheles spp. collected in the Province of Trento (Italy) by species, sex and municipality (2008-2018)

\begin{tabular}{|c|c|c|c|c|c|c|c|c|c|}
\hline \multirow[t]{2}{*}{ Municipality/species } & \multirow{2}{*}{$\begin{array}{l}\text { An. claviger } \\
\text { F }\end{array}$} & \multicolumn{2}{|c|}{ An. maculipennis s.l. } & \multicolumn{2}{|c|}{ An. maculipennis s.s. } & \multicolumn{2}{|c|}{ An.plumbeus } & \multicolumn{2}{|c|}{ Anopheles spp. } \\
\hline & & $\mathbf{F}$ & $M$ & $\mathbf{F}$ & $M$ & $\mathbf{F}$ & $M$ & $F$ & $M$ \\
\hline ALA & & & & & 1 & & & & \\
\hline ARCO & 3 & 27 & 5 & 1 & & 6 & & 12 & 4 \\
\hline CAMPODENNO & 1 & & & & & & & & \\
\hline CASTEL IVANO $^{\mathrm{a}}$ & 1 & & & & & 40 & 1 & & \\
\hline CAVEDINE ${ }^{\mathrm{b}}$ & & & & & & 1 & & & \\
\hline \multicolumn{10}{|l|}{ CIVEZZANO ${ }^{\mathrm{a}, \mathrm{b}}$} \\
\hline \multicolumn{10}{|l|}{ COREDO $^{a, b}$} \\
\hline DENNO & 1 & & & & & & & & \\
\hline DRENA ${ }^{a, b}$ & & & & & & 1 & & & \\
\hline DRO & & & & & & 1 & & 1 & \\
\hline GRIGNO & 4 & & & 1 & & 13 & & 1 & \\
\hline MADRUZZO & & & 1 & & & 1 & & 1 & \\
\hline MEZZOCORONA & & & & & & 1 & & & \\
\hline MEZZOLOMBARDO & & & & & & 1 & & & \\
\hline RIVA DEL GARDA & & 11 & 4 & & & 4 & & 6 & 2 \\
\hline \multicolumn{10}{|l|}{ RONCEGNO TERME ${ }^{a, b}$} \\
\hline SAN MICHELE A/A & & & & 2 & & 6 & & & \\
\hline TELVE & & & & & & 8 & & & \\
\hline TENNO & & & 1 & & & 16 & & & \\
\hline TRENTO & & 1 & & 1 & & 15 & 2 & & \\
\hline ZAMBANA & & & & & & 1 & & & \\
\hline Total & 10 & 39 & 11 & 5 & 1 & 115 & 3 & 21 & 6 \\
\hline
\end{tabular}

s.l., sensu lato; s.s., sensu stricto; spp., species pluralis

a Presence of larval stage; $F=$ adult female; $M=$ adult male; $A n=$ Anopheles

b Sites visited only once in the study period 2008-2018

a possible intraspecific heterogeneity, a random sample of 103 Anopheles specimens (49\%) was processed, yielding ITS-2 sequences according to a previously described procedure [4, 9]. For 5 specimens of An. plumbeus, a fragment of the mtDNA COI (735 bp) was also characterized. COI and ITS-2 sequences were analyzed by DS gene 1.5 (Accelrys Inc., Cambridge), and then submitted to GenBank (accession no. MK618768-72; MK625341-6; MK625347-426; MK625428-33).

\section{Results}

A total of 67 sites $(23 \%$; $67 / 287)$ resulted positive for the presence of immature or adult stages of Anopheles spp. (Fig. 1). In total 211 individuals were collected: 118 (56\%) belonged to An. plumbeus, 56 (26.5\%) to An. maculipennis complex, 10 (4.7\%) to An. claviger and 27 were identified only at genus level (Table 1). Of note, the capture of Anopheles mosquitoes from our entomological surveillance, represents the $0.37 \%$ of all the mosquito samples collected. This is the first record for An. plumbeus in the study area.
About $49 \%(n=103)$ of the samples already identified morphologically was processed at molecular level, generating ITS-2 sequences of An. plumbeus $(\mathrm{n}=80), A n$. maculipennis s.s. $(\mathrm{n}=6)$ and An. claviger $(\mathrm{n}=6)$; unfortunately 11 sequences failed. For An. plumbeus and $A n$. maculipennis sensu stricto (s.s.) no intraspecific variations were detected in the samples examined, whereas three variable sites were detected for An. claviger, identifying three haplotypes. In addition, the five COI sequences of An. plumbeus shared $100 \%$ identity with a sequence of such species from Austria (KM280577).

\section{Discussion}

At the end of the 19th century Italy was one of the most endemic European countries for malaria with about 15,000-20,000 deaths per year [10]. As a result of an extensive and integrated approach to fight against this disease, Italy was declared malaria-free by the World Health Organization in 1970. Since then, the Italian surveillance system detected a rise in the malaria cases $(700$ per year from 2000 to 2008 [11]). Nonetheless, the malariogenic potential in Italy has to be considered low [12] 
due to the very small number of authochtonous cases (0.1\% from 2000 to 2008 [11]), and the few and scattered mosquito species that can transmit Plasmodium spp. The lack of detailed or updated data in some areas of Italy makes it crucial to fill the gaps and improve the surveillance system in order to better assess possible risks.

The Province of Trento borders with historically known and suitable malaria areas such as the Padana valley, but has never been considered important for mosquito presence because of its mountainous features. Due to this, the only previous data on Anopheles spp. distribution, dates back to the $60 \mathrm{~s}$ [13] and reported the presence of An. maculipennis s.s. and An. claviger, both species considered refractory to Plasmodium spp. transmission [3, 26]. In this study it has been confirmed the presence of the above-mentioned species, but the presence of $A n$. plumbeus has been recorded for the first time.

Anopheles plumbeus is a Palearctic species widely distributed throughout Europe (except the far northern regions), the Middle East and North Africa [7]. It can be found in forested areas from sea level up to $1200 \mathrm{~m}$ a.s.l. [14], where it preferentially breeds in water-filled tree holes, although females can also exploit other artificial breeding sites where to lay the eggs such as catch basins, tires, cemetery vases and domestic and peridomestic containers near human settlements, especially large manure pits [15]. Among all the specimens collected in this survey, An. plumbeus was the most abundant and wide distributed, although at low density. This species has recently become important for its role in malaria cryptic transmission cycles, provided the presence of gametocyte carriers in the area [3]. In particular its susceptibility to $P$. falciparum in experimental infections $[3,16,17]$ and its longevity [3] that enables the Plasmodium parasites to complete their development to the oocyst and sporozoite stages make it suitable as a potential malaria vector [18]. Moreover, the ability to exploit man-made artificial breeding habitat and its anthropophilic behaviour, may favour an increase of the population numbers and its nuisance, as recently reported in Belgium [15], with potential consequences on public health risk. Furthermore, $A n$. plumbeus can also produce sporozoites of Plasmodium vivax $[19,20]$ and some studies reported that it may have a considerable role in the maintainance of West Nile virus or even dirofilariasis [7, 21].

Anopheles maculipennis s.s. is the only species belonging to the An. maculipennis complex previously reported in the Province of Trento [13]. Among the collected individuals, $11 \%$ were molecularly analysed and confirmed as An. maculipennis s.s. Although this group has been historically recognized important for its involvement in the malaria transmission in Europe, it was shown that afrotropical $P$. falciparum strains-cause of the vast majority of imported malaria in Europe-are not well adapted to this complex of species [22-24]. Finally, An. claviger which is found throughout the Palearctic and is quite widespread in Italy $[13,25]$, is considered only an occasional vector for malaria [26, 27]. An evident intraspecific polymorphism has been found in An. claviger, which needs to be further investigated. The presence of individuals belonging to An. maculipennis s.s. and An. claviger in the Province of Trento (Italy) is to be considered negligible.

Plasmodium spp. transmission in malaria-free countries by local Anopheles mosquito species has progressively increased due to global changes and mass population movements [28]. In particular, P. falciparum completion of the sporogonic cycle in a gametocyte-fed, wild An. plumbeus requires an extended and continuous period of elevated temperatures. The recorded global increase in frequency, intensity and duration of heat events could affect it, however the epidemiological settings for malaria are not only linked to climatic factors. Following the fatal case reported in September 2017 and the lack of updated information on the distribution of Anopheles spp. in the Province of Trento (Italy) [13], this study represents a first step toward a better knowledge on the presence of this genus. Moreover, recent outbreaks of other mosquito-borne diseases other than malaria (e.g. West Nile, Chikungunya and Dengue viruses), demonstrate the importance of gathering as much information as possible on potential vectors presence and distribution, and this holds true especially for invasive mosquito species than can have both an economic and a human health impact.

\section{Conclusions}

The aim of this study was to investigate the potential spatial distribution of Anopheles spp. mosquitoes in the Province of Trento, Italy. The presence of An. plumbeus, a potential malaria vector, has been recorded, but by now, the rare presence of the vector, the good malaria notification system, the prompt treatment of patients with imported malaria and the low probability of the vector to encounter a gametocyte carrier, are unlikely to facilitate an epidemic in the area. Nonetheless, as the global situation is dynamic and variable, gardens and urban parks, as well as other potential breeding sites such as catch basins or septic tanks, should be constantly monitored for the presence of mosquitoes, to provide updated information on the occurrence and dynamic of malaria and other emerging mosquito-borne diseases vectors.

\section{Abbreviations}

An: Anopheles; s.l.: sensu lato; s.s.: sensu stricto; spp.: species pluralis; P.

Plasmodium. 


\section{Authors' contributions}

$V T, D A, A R$ conceived and drafted the paper; DA performed the samples collection; $\mathrm{MDL}$, LT performed the molecular screening of the samples. All authors read and approved the final manuscript.

\section{Author details}

${ }^{1}$ Fondazione Edmund Mach, Research and Innovation Centre, Via E. Mach 1, San Michele all'Adige, Trento, Italy. ${ }^{2}$ Department of Infectious Diseases, Istituto Superiore di Sanità, Viale Regina Elena, Rome, Italy.

\section{Acknowledgements}

The authors are grateful to L. Gradoni for his helpful suggestions and for reviewing the manuscript. We would like to thank all the people who helped in the field and in particular: Baldacchino Frederic, Bergamini Raul, Bussola Francesca, Grisenti Michela, Inama Enrico, and Roiz David, and Severini Francesco for his technical support. Special thanks go to our colleagues Manica Mattia and Delucchi Luca for the statistical and data management support. Finally, we are also grateful to the two anonymous reviewers for their valuable comments to the manuscript.

\section{Competing interests}

The authors declare that they have no competing interests.

\section{Availability of data and materials}

Not applicable.

\section{Consent for publication}

Not applicable.

\section{Ethics approval and consent to participate}

Not applicable.

\section{Funding}

This work was carried out in the framework of Project LExEM (Laboratory of Excellence for Epidemiology and Modelling, http://www.lexem.eu).

This study was supported by Provincia Autonoma di Trento (Grant Grandi Progetti).

\section{Publisher's Note}

Springer Nature remains neutral with regard to jurisdictional claims in published maps and institutional affiliations.

Received: 31 January 2019 Accepted: 22 April 2019

Published online: 29 April 2019

\section{References}

1. Piperaki ET, Daikos GL. Malaria in Europe: emerging threat or minor nuisance? Clin Microbiol Infect. 2016:22:487-93.

2. ECDC. Rapid risk assessment: hospital-acquired malaria infections in the European Union. Stockholm. 30 April 2018

3. Schaffner F, Thiéry I, Kaufmann C, Zettor A, Lengeler C, Mathis A, et al. Anopheles plumbeus (Diptera: Culicidae) in Europe: a mere nuisance mosquito or potential malaria vector? Malar J. 2012;11:393.

4. Di Luca M, Boccolini D, Severini F, Toma L, Mancini Barbieri F, Massa A et al. A 2-year entomological study of potential malaria vectors in Central Italy. Vector Borne Zoonotic Dis. 2009;9:703-11.

5. Bietolini S, Candura F, Coluzzi M. Spatial and long term temporal distribution of the Anopheles maculipennis complex species in Italy. Parassitologia. 2006:48:581-608
6. Neteler M, Roiz D, Rocchini D, Castellani C, Rizzoli A. Terra and Aqua satellites track tiger mosquito invasion: modelling the potential distribution of Aedes albopictus in north-eastern Italy. Int J Health Geogr. 2011:10:49.

7. Schaffner F, Angel G, Geoffroy B, Hervy J-P, Rhaiem A, Brunhes J. The mosquitoes of Europe. An identification and training programme. CD Rom. IRD Editions \& EID Méditerranée, Montpellier; 2001.

8. Becker N, Zgomba M, Petric D, Dahl C, Boase C, Lane J, et al. Mosquitoes and their control. 2nd ed. Berlin: Springer Science \& Business Media; 2013.

9. Marinucci M, Romi R, Mancini P, Di Luca M, Severini C. Phylogenetic relationship of seven Palearctic members of the maculipennis complex (Diptera: Culicidae) inferred from ITS2 analysis. Insect Mol Biol. 1999:8:469-80.

10. Majori G. Short history of malaria and its eradication in Italy with short notes on the fight against the infection in the mediterranean basin. Mediterr J Hematol Infect Dis. 2012;4:e2012016.

11. Romi R, Boccolini D, D'Amato S, Majori G. Malaria surveillance in Italy: the 2000-2008 national pattern of imported cases. Giornale Italiano Med Trop. 2010;15:35-8.

12. Romi R, Sabatinelli G, Majori G. Could malaria reappear in Italy? Emerg Infect Dis. 2001;7:915-9.

13. Raffaele G. Note sull'eradicazione della malaria in Italia. Riv Malariol. 1964:43:1-27

14. Senevet $G$, Andarelli L. Les anophèles de l'Afrique du nord et du Bassin méditerranéen. Ed. Paris: Le Chevalier; 1956.

15. Dekoninck W, Hendrickx F, Van Bortel W, Versteirt V, Coosemans M, Damiens D, et al. Human-induced expanded distribution of Anopheles plumbeus, experimental vector of West Nile virus and a potential vector of human malaria in Belgium. J Med Entom. 2011:48:924-8.

16. Marchant P, Eling W, van Gemert GJ, Leake CJ, Curtis CF. Could British mosquitoes transmit falciparum malaria? Parasitol Today. 1998;14:344-5.

17. Eling W, van Gemert GJ, Akinpelu O, Curtis J, Curtis CF. Production of Plasmodium falciparum sporozoites by Anopheles plumbeus. Eur Mosa Bull. 2003;15:12-3.

18. Krüger A, Rech A, Su XZ, Tannich E. Two cases of autochthonous Plasmodium falciparum malaria in Germany with evidence for local transmission by indigenous Anopheles plumbeus. Trop Med Int Health. 2001;6:983-5.

19. Blacklock B, Carter HF. The experimental infection, in England, of Anopheles plumbeus with Plasmodium vivax (sporozoites in salivary glands). Preliminary note. Ann Trop Med Parasitol. 1919:13:187-8.

20. Shute PG. Indigenous P. vivax malaria in London believed to have been transmitted by Anopheles plumbeus. Mon Bull Ministry Health Public Health Lab Serv. 1954;13:48-51.

21. Vermeil C, Lavillaureix J, Reeb E. On the preservation and transmission of the West Nile virus by some arthropods. Bull Soc Pathol Exot. 1960:53:273-9 (in French).

22. Shute PG. Failure to infect English specimens of Anopheles maculopennis var. atroparvus with certain strains of Plasmodium falciparum of tropical origin. J Trop Med Hyg. 1940:43:175-8.

23. de Zulueta J, Ramsdale CD, Coluzzi M. Receptivity to malaria in Europe. Bull World Health Organ. 1975:52:109-11.

24. Ramsdale CD, Coluzzi M. Studies on the infectivity of Tropical African strains of Plasmodium falciparum to some Southern European vectors of malaria. Parassitologia. 1975;17:39-48.

25. Severini F, Toma L, Di Luca M, Romi R. Le zanzare italiane: generalità e identificazione degli adulti (Diptera, Culicidae). Frag Entomol. 2009:41:213-372.

26. Postiglione M, Tabanli S, Ramsdale CD. Anopheles claviger in Turkey. Riv Parassitol. 1972:33:219-30.

27. Alten B, Çaglar S, Özer N. Malaria and its vectors in Turkey. Eur Mosq Bull. 2000;7:27-33.

28. ECDC. Rapid risk assessment: Multiple reports of locally-acquired malaria infections in the EU. Stockholm. 20 September 2017. 